\title{
Child safety seat usage errors in under-4s
}

\author{
Sergio Ricardo Lopes de Oliveira, ${ }^{1}$ Cláudio Leone, ${ }^{2}$ Maria Dalva de Barros Carvalho, ${ }^{3}$ \\ Rosângela Getirana Santana, ${ }^{4}$ Ludmila Elaine Lüders, ${ }^{5}$ Fernanda Cabrera Oliveira ${ }^{6}$
}

\begin{abstract}
Objective: To analyze child safety seat usage errors among children enrolled at daycare.

Methods: This was a cross-sectional, observational study with prospective data collection and a retrospective analytical axis.

Results: Overall, $42.7 \%$ of the children studied were in incorrectly used seats. A logistic regression model showed that the likelihood of usage errors was higher if there were two or more children in the vehicle (odds ratio $=5.10$, $p=0.007$ ) and was dependent on parents' educational level and income (medium income and educational level: odds ratio $=7.00, p=0.003$; low income and educational level: odds ratio $=3.40, p=0.03$ ).
\end{abstract}

Conclusion: The results of this study are in line with findings reported in international publications.

J Pediatr (Rio J). 2012;88(4):297-302: Child safety seats, traffic accidents, accident prevention, seatbelts.

\section{Introduction}

Accidents, and traffic accidents in particular, have a significant impact on mortality in developed countries and the same is true of Brazil.1,2 Child safety seats (CSS) are designed to restrain child passengers in automobiles, in order to reduce deaths and other sequelae. When used correctly they can reduce the likelihood of death by $71 \% .^{3}$ Although the legislation in many countries including Brazil ${ }^{4}$ makes it obligatory to use CSS, international data show that they are often ignored or used incorrectly ${ }^{5}$ and that as children get older CSS use drops off. ${ }^{6}$ Data from the United States' National Highway Traffic Safety Administration? showed that an estimated $80 \%$ of CSS are being misused when inspected.

Resolution 277/08 from the Brazilian National Traffic Board (CONTRAN - Conselho Nacional de Trânsito) 4 came into force in September of 2010. This resolution was a significant legal advance, since it regulates the use of CSS in Brazil, laying down criteria for their use based on children's ages.

A study of CSS use was conducted recently with children under 4 enrolled at daycare in the city of Maringá, PR, and found that the rate of CSS use was $36.1 \%$ and that use was

1. PhD. Adjunct professor, Departamento de Medicina, Universidade Estadual de Maringá (UEM), Maringá, PR, Brazil.

2. Tenured professor, Departamento de Saúde Materno-Infantil, Faculdade de Saúde Pública, Universidade de São Paulo (USP), São Paulo, SP, Brazil.

3. PhD. Associate professor, Departamento de Medicina, UEM, Maringá, PR, Brazil.

4. PhD. Associate professor, Departamento de Estatística, UEM, Maringá, PR, Brazil.

5. Pediatric resident, Departamento de Medicina, UEM, Maringá, PR, Brazil.

6. Internal Medicine resident, Departamento de Medicina, UEM, Maringá, PR, Brazil.

The present article was based on the first author's doctoral dissertation, entitled "Erros da utilização de assentos de segurança infantil por usuários de creches na cidade de Maringá, Paraná" ("Child safety seat usage errors in children attending daycare centers in the municipality of Maringá, state of Paraná"), presented in 2010 at Faculdade de Saúde Pública, Universidade de São Paulo (USP), in São Paulo, SP, Brazil.

No conflicts of interest declared concerning the publication of this article.

Suggested citation: de Oliveira SR, Leone C, Carvalho MD, Santana RG, Lüders LE, Oliveira FC. Child safety seat usage errors in under-4s. J Pediatr (Rio J). 2012;88(4):297-302.

Manuscript submitted Dec 26 2011, accepted for publication Mar 092012.

http://dx.doi.org/10.2223/JPED.2189 
related to income and educational level of the head of the household, the child's age and whether or not the driver used a seatbelt. ${ }^{8}$ The first Brazilian studies of this subject have only been published recently. ${ }^{9-11}$

Against this background of incipient legislation and a shortage of Brazilian data, the objectives of this study were to describe the rate of CSS misuse among under-4s enrolled at day care, identify the most common usage errors and analyze factors related to misuse.

\section{Methods}

This was a cross-sectional, observational study with prospective data collection and a retrospective analytical axis using a database originally compiled as part of a research project to measure the rate of CSS use among children attending daycare in the city of Maringá, which was conducted from March to June in 2007.8 The target population was 1,005 children aged 0 to 4 years enrolled at 32 daycare centers. These daycare centers were classified according to educational level and income of head of the household into one of four strata: A - private daycare centers in areas with high income and educational level; $\mathrm{B}$ - private daycare centers in areas with medium income and educational level; C - private daycare centers in areas with low income and educational level; D - public day care centers in areas with high income and educational level. These strata were chosen because they concentrate $62.4 \%$ of children who are transported in automobiles, according to a preliminary study conducted to measure the rate of use of automobiles as a means of transport to attend daycare centers. ${ }^{12}$

For this population, the sample size was estimated at 283 children for a 5\% error and 95\% confidence interval. The sample was stratified in proportion to the size of each strata and data collection began at the daycare center with the largest population and continued in descending order of number of children enrolled until the sample size for each strata had been passed. Each daycare center was only studied on one school day and only the principal of each institution was informed of the date in advance. People bringing children to daycare centers by car were approached when they arrived and asked to take part in the study. Two previously trained data collectors were assigned to each car and administered semi-structured questionnaires that had been tested in advance in a pilot study. ${ }^{13}$

The instruments had been developed in order to obtain information on the sex of the occupants of the vehicle, whether the driver used a seatbelt, the restraint status of adult and child passengers, in addition to presence and utilization of CSS, and the distribution of adults and children on the vehicle's seating. Excluding the driver's seat, the remaining positions in the car were labeled as follows: A - front passenger seat; B - rear, behind passenger; C - rear, center; D - rear, behind driver.

During the data collection process, one data collector approached the driver, explained the research to them and offered the consent form. The same collector then took details on sex, age and weight of the children and the sex of the driver and any other adults, while the other collector observed the restraint status of the driver and the other passengers and their positions within the vehicle. A study conducted by Decina et al. ${ }^{5}$ defined the principal CSS use errors as follows: using equipment that is inappropriate for the child's age and/or weight (selection error), inadequate restraint of child by straps or seatbelts (restraint error) and inadequate installation in the vehicle (installation error). ${ }^{5}$ The methodology adopted for this study covers selection and restraint errors, but not installation errors, since this would have required extensive inspections, which were not conducted.

Standards published by the American Academy of Pediatrics (AAP), ${ }^{14}$ the Royal Society for the Prevention of Accidents (ROSPA $)^{15}$ and the Brazilian Society of Pediatrics (Sociedade Brasileira de Pediatria, SBP) ${ }^{16}$ use children's age and weight to determine which type of CSS should be used and recommend that the manufacturer's instructions should be followed. CONTRAN resolution $277 / 08^{4}$ only uses age to determine which type of CSS should be used. For the purposes of this study, the age criterion was considered most relevant since there were very few children less than 12 months old. Table 1 lists the types of CSS that should be used, by numbered age group, according to CONTRAN resolution 277/08.4 Selection errors were defined as disagreement between child's age group and CSS type being used; i.e., children in age group 0 using a type 1 CSS would be a selection error, as would a child in age group 1 using a type 2 CSS.

Types 1 and 2 CSS have restraining straps to secure the child (restraining CSS). For these CSS, restraint errors were defined as not using the straps or straps that were clearly too loose. Type 2 CSS do not have restraint straps and are designed to use the vehicle's seat belts to restrain the occupant (non-restraining CSS). For these types of CSS, a restraint error was not wearing the seatbelt. Type 2 CSS are obviously intended for children older than 4 and, therefore, are not suitable for the study population, but children under 4 were observed on type 2 CSS (booster seats), which were duly recorded as selection errors. These data were not excluded from analysis and the results will be discussed in the appropriate place.

Data were analyzed using Fisher's exact test, the MantelHaenszel chi-square test and multiple logistic regression using Epi-Info 3.3.2 and Statistica 8.1.

The study was approved by the Research Ethics Committee at the Universidade Estadual de Maringá 
Table 1 - Definition of children's age groups and child safety seat types, Maringá, 2007

\begin{tabular}{lcc}
\hline & Child's age & CSS type \\
\hline Group 0 & Less than 11 months & Carrycot or rear-facing child seat \\
Group 1 & 12 to 47 months & Forward-facing child seat \\
Group 2 & 48 to 90 months & Booster seats \\
\hline
\end{tabular}

CSS $=$ child safety seat

(COEP/UEM) (hearings 271/2006 and 001/2009) and by the Human Research Ethics Committee at the Universidade de São Paulo Faculty of Public Health (COEP/FSP/USP) (COEP report 043/09).

\section{Results}

The drivers of 370 automobiles were approached; 301 of these were transporting children eligible for the study, to a total of 324 children aged 0 to 4 years. Only $36.1 \%$ of them were being transported in a CSS, as has already been reported by Oliveira et al. ${ }^{8}$ The analysis presented here is of the 117 children (36.1\% of 324) who were in a CSS. Fifty of the 117 children (42.7\%) who were in a CSS were in one that was being used incorrectly. In the cases of two children $(1.7 \%)$ it was not possible to ascertain whether or not they were restrained or wearing seatbelts.

A total of 54 usage errors were detected (15 selection and 39 retention errors) in 50 children, because four children were in the wrong type of CSS for their ages and were also not restrained properly (Table 2 ). Table 3 lists the results of the univariate analysis and Table 4 lists the results of the logistic regression for the usage errors observed. Logistic regression analyses were conducted separately for each type of error, selection and restraint (data not shown). The logistic regression for selection errors showed that children in age group 0 were significantly more likely to be in a type 1 CSS (odds ratio [OR] $=13.75, p<0.01$ ), which equates to children less than 12 months old facing forwards, rather than rearwards.

Table 2 - Child safety seat usage errors summarized by group, Maringá, 2007

\begin{tabular}{lcc}
\hline & \multicolumn{2}{c}{ Proportion } \\
\cline { 2 - 3 } Usage errors observed & $\mathbf{n}$ & $\mathbf{( \% )}$ \\
\hline Selection errors & & \\
Child in age group 0 in type $1 \mathrm{CSS}^{*}$ & 9 & 16.7 \\
Child in age group 1 in type 2 CSS & 6 & 11.1 \\
Restraint errors & & 68.5 \\
$\quad$ Types 0 or 1 CSS, strap use error & 37 & 3.7 \\
$\quad$ Type 2 CSS, not wearing seatbelt & \\
Total & 2 & 100 \\
\hline
\end{tabular}

CSS $=$ child safety seat

* Two children from group 0 were in type 1 CSS and were also incorrectly restrained.

$\dagger$ Both children in type 2 CSS who were not wearing seatbelts were in age group 1. 


\section{Discussion}

The results showed that $42.7 \%$ (50/117) of the children being transported in CSS were in some way incorrectly seated, whether because the CSS was of the wrong type, because they were incorrectly restrained, or both. Recent international publications with a variety of research methodologies have found the same situation. ${ }^{17-19}$

Table 3 - Univariate analysis of child safety seat usage errors against factors of interest, Maringá, 2007

\begin{tabular}{|c|c|c|c|c|}
\hline \multirow[b]{2}{*}{ Variables } & \multicolumn{2}{|c|}{ cSS usage (n) } & \multirow[b]{2}{*}{ Raw OR MH } & \multirow[b]{2}{*}{$\mathbf{p}$} \\
\hline & Incorrect & Correct & & \\
\hline Position of seat* & & & 1.05 & 0.98 \\
\hline Position B & 21 & 28 & 1.00 & \\
\hline Position C & 18 & 25 & 0.96 & 0.92 \\
\hline Position D & 11 & 12 & 1.22 & 0.69 \\
\hline Sex of child ${ }^{+}$ & & & 1.82 & 0.14 \\
\hline Male & 31 & 33 & & \\
\hline Female & 15 & 29 & & \\
\hline Age group for purposes of CSS usage & & & 6.53 & $<0.01$ \\
\hline Age group 0 & 12 & 3 & & \\
\hline Age group 1 & 38 & 62 & & \\
\hline Type of CSS & & & 6.91 & $<0.01^{\ddagger}$ \\
\hline Not self-contained seat (carrycot or booster seat) & 9 & 2 & & \\
\hline Self-contained seat & 41 & 63 & & \\
\hline Sex of driver ${ }^{+}$ & & & 1.32 & 0.48 \\
\hline Male & 20 & 22 & & \\
\hline Female & 29 & 42 & & \\
\hline Driver wearing seatbelt & & & 0.71 & 0.40 \\
\hline Unrestrained & 14 & 23 & & \\
\hline Restrained & 36 & 42 & & \\
\hline Interaction between sex of driver and wearing a seatbelt ${ }^{\dagger}$ & & & 0.88 & 0.77 \\
\hline Man, no seatbelt & 8 & 9 & 1.08 & 0.88 \\
\hline Man, with seatbelt & 12 & 13 & 1.12 & 0.81 \\
\hline Man, no seatbelt & 6 & 14 & 0.52 & 0.24 \\
\hline Woman, with seatbelt & 23 & 28 & 1.00 & \\
\hline Daycare center strata & & & 2.81 & $<0.01$ \\
\hline Stratum A & 16 & 37 & 1.00 & \\
\hline Stratum B & 9 & 5 & 4.16 & 0.019 \\
\hline Stratum C & 12 & 8 & 3.47 & 0.02 \\
\hline Stratum D & 13 & 15 & 2.00 & 0.14 \\
\hline Number of passengers in vehicle & & & 1.93 & 0.08 \\
\hline Two or more & 24 & 21 & & \\
\hline One & 26 & 44 & & \\
\hline Number of children in vehicle & & & 4.67 & $<0.01$ \\
\hline Two or more & 14 & 5 & & \\
\hline One & 36 & 60 & & \\
\hline Number of adult passengers & & & 1.08 & 0.86 \\
\hline One or more & 13 & 16 & & \\
\hline None & 37 & 49 & & \\
\hline
\end{tabular}

CSS = child safety seat; $\mathrm{MH}=$ Mantel-Haenszel chi-squared test; OR = odds ratio.

* No CSS were fitted in position A.

$\dagger$ There were data collection errors for these variables (the sexes of seven children and three drivers were not identified) leading to losses of less than $10 \%$ for each variable.

‡ Fisher's exact test. 
Table 4 - Logistic regression model for variables associated with child safety seat usage errors, Maringá, 2007

\begin{tabular}{lcc}
\hline Variable & OR & p \\
\hline Child in age group 0 & 0.08 & 0.14 \\
Age less than 12 months & 0.60 & 0.74 \\
Daycare center in stratum B & 7.0 & 0.003 \\
Daycare center in stratum C & 3.4 & 0.03 \\
Daycare center in stratum D & 1.6 & 0.34 \\
More than one child passenger & 5.1 & 0.007 \\
\hline
\end{tabular}

OR = odds ratio

In 2005 , Staunton et al. ${ }^{20}$ described a very similar study to this one since it used the same data collection methodology: i.e. observation of vehicle occupants and administration of a questionnaire requesting only data on age and weight of the child passengers, although only aiming to investigate selection errors. Irrespective of age, $42 \%$ of children in a CSS were being transported incorrectly.

In this study, restraint errors were the principal error observed, accounting for $72.2 \%$. Of particular note was the proportion of unstrapped or too loosely strapped children in types 0 and 1 CSS, which was observed in $68.5 \%$ of the children in these types of seats. These types of error can lead to negation of the seat's ability to secure the child during braking, cornering, collisions and rolls, in addition to not preventing the child from voluntarily moving around inside the vehicle. ${ }^{11}$

For these children from Maringá, incorrect CSS use was statistically related to attending daycare centers in strata B or C (medium and low incomes and educational level, respectively), both comprising private daycare centers. These observations indicate that high income and educational level, both present in strata $A$ and $D$, was more significant than daycare center type (private or public) in terms of correct CSS use. These findings are in line with the international literature which has reported higher rates of CSS use in more privileged populations and lower rates in less privileged strata. $6,21,22$

Another factor linked to higher rates of CSS usage errors was the presence of more than one child in the automobile. The presence of two or more children increased the likelihood of CSS usage errors by five times. This is understandable, since correct CSS use is dependent on observation of many different details of usage. Similar results have been observed in international studies. 23,24

In $16.7 \%$ of the children there was premature promotion of children from type 0 to type 1 . These children were in forward-facing CSS when they should still have been in rear-facing seats. The logistic regression for selection errors makes the relevance of this variable clear $(\mathrm{OR}=13.75$, $\mathrm{p}<0.01$ ). Premature promotion of children to type 1 seats was also observed in $28 \%$ of infants under 12 months by Staunton et al. ${ }^{20}$ According to Simpson et al., ${ }^{25}$ seating children facing forwards prematurely was the principal serious error observed, in $13 \%$ of the sample.

As discussed in the methods section, it should not have been necessary to investigate type 2 CSS usage in children less than 4 years old. However, this selection error (premature use of booster seats) accounted for $11.1 \%$ of usage errors (Table 2 ). Morris et al. 26 reported that $50 \%$ of booster seat users were doing so prematurely. In a Canadian study, this rate was $15 \% .{ }^{18} \mathrm{~A}$ Belgian study, ${ }^{17}$ analyzing 1,376 children, found that $38.6 \%$ of the children from 1 to 3 years old were in booster seats prematurely.

Returning to the result that $42.7 \%(50 / 117)$ of children transported in CSS were in CSS that were in some way being used incorrectly, and starting from a basic rate of CSS use of around $36.1 \%(117 / 324),{ }^{8}$ the conclusion is that just $20.6 \%(67 / 324)$ of children less than 4 years old enrolled at daycare centers in the city of Maringá were in a CSS correctly chosen for their age and with no obvious restraint errors. However, it still cannot be categorically stated that $20.6 \%$ of the children observed were in CSS being used correctly, since significant classes of CSS usage errors were not covered by the methodological design employed. Whether or not the CSS is correctly installed in a vehicle can only be determined after detailed inspection. Additionally, the protocol recorded loose retention straps or no strap usage, but may have missed more subtle errors.

This data must be considered in the knowledge that it was collected before CONTRAN resolution 277/08 was enacted. ${ }^{4}$ Despite being much-needed, this legislation is already obsolete and overly simplistic when compared with $\mathrm{AAP}^{14}{ }^{14} \mathrm{ROSPA}^{15}$ and SBP, ${ }^{16}$ recommendations, particularly with reference to children's weight for correct CSS use, and because it does not encourage infants to be kept rearwardfacing for as long as possible.

It is not only in Brazil that legislation is in its infancy. In China, the largest of the emerging countries, there are no laws on CSS. ${ }^{27}$ In Japan, the law has been in existence since 2000 and mandates CSS for children up to 5 year old. ${ }^{28}$ It is only recently that Australian law has increased the coverage of mandatory CSS usage from 1 to 7.5 years. Previously CSS were only obligatory for children less than 1 year old. ${ }^{29}$ Enactment of specific legislation has proved to be an effective and rapid strategy for increasing CSS usage. ${ }^{30}$

Given the recent enactment of Brazilian legislation on the subject, it is expected that the law will have an impact on the rate of CSS use and that it may also affect usage errors. Another study, with the same population described in this article, has already been started in order to measure this impact. 


\section{References}

1. Waksman RD, Pirito RM. Injúrias não intencionais: acidentes de trânsito. In: Lopes FA, Campos Jr D, orgs. Tratado de pediatria. São Paulo: Editora Manole; 2007. p. 89-93.

2. Judy K. Unintentional injuries in pediatrics. Pediatr Rev. $2011 ; 32: 431-9$

3. Winston FK, Durbin DR, Kallan MJ, Moll EK. The danger of premature graduation to seat belts for young children. Pediatrics. 2000;105:1179-83.

4. Conselho Nacional de Trânsito (CONTRAN). Resolução no 277 , de 28 de maio de 2008. Dispõe sobre o transporte de menores de 10 anos e a utilização do dispositivo de retenção para o transporte de crianças em veículos. http://www.denatran.gov.br/ download/Resolucoes/RESOLUCAO_CONTRAN_277.pdf. Access: 02/10/10.

5. Decina LE, Lococo $\mathrm{KH}$. Child restraint system use and misuse in six states. Accid Anal Prev. 2005;37:583-90

6. Brixey S, Guse CE, Meurer J. Booster seat use in an inner-city day care center population. Traffic Inj Prev. 2008;9:238-42.

7. Daniels WL. A review of current technology in child safety seats for infants. J Pediatr Health Care. 2006;20:419-23.

8. Oliveira SR, Carvalho MD, Santana RG, Camargo GC, Lüders L, Franzin S. Child safety restraint use among children attending day carecenters. Rev Saude Publica. 2009;43:761-7.

9. Waksman RD, Pirito RM. The pediatrician and traffic safety. J Pediatr (Rio J). 2005;81:S181-8.

10. Souza BG, Souza FG, Souza TG, Souza AM, Souza VG, Afonso VW. Use profile of protective devices for children in vehicles among patients from a private pediatrics' clinic. HU rev. 2006;32:97-102.

11. Oliveira SR, Carvalho MD, João PR. Normas de segurança para o transporte de crianças em automóveis. Pediatria (São Paulo). 2007;29:129-43.

12. Oliveira SR, Carvalho MD, Previdelli IM. Family car use for transportation of children: a preliminary study of the use of child car seats. Rev Bras Saude Mater Infant. 2008;8:499-502.

13. Oliveira SR, Carvalho MD, Santana RG, Kawazoe CH, Santos EQ, Oliveira FC. Analysis of research methodologies about the use of child restraint systems: lessons of a pilot project. Rev Paul Pediatr. 2008;26:119-23.

14. Committee on Injury, Violence, and Poison Prevention, Durbin DR. Child passenger safety. Pediatrics. 2011;127:788-93.

15. Child Car Seats. Carrying Children Safely. http://www.childcarseats. org.uk/carrying_safely/carrying_safely.htm. Access: 08/02/12.

16. Sociedade Brasileira de Pediatria. Departamento Científico de Segurança da Criança e do Adolescente. Transporte seguro de crianças como passageiras de automóveis. http://www. conversandocomopediatra.com.br/paginas/materias_gerais/ transporte_seguro_criancas.aspx. Access: 08/02/12.
17. Vesentini $L$, Willems B. Premature graduation of children in child restraint systems: an observational study. Accid Anal Prev. 2007;39:867-72.

18. Blair J, Perdios A, Babul S, Young K, Beckles J, Pike I, et al. The appropriate and inappropriate use of child restraint seats in Manitoba. Int J Inj Contr Saf Promot. 2008;15:151-6.

19. Koppel S, Charlton JL. Child restraint system misuse and/or inappropriate use in Australia. Traffic Inj Prev. 2009;10:302-7.

20. Staunton C, Davidson S, Kegler S, Dawson L, Powell K, Dellinger A. Critical gaps in child passenger safety practices, surveillance, and legislation: Georgia, 2001. Pediatrics. 2005;115:372-9.

21. Schluter PJ, Paterson J. Vehicle child restraint usage for Pacific children aged 6 weeks to 4 years: findings from the Pacific Islands Families study. Accid Anal Prev. 2010;42:2075-81.

22. Snowdon AW, Hussein AA, Ahmed SE. Children at risk: predictors of car safety seat misuse in Ontario. Accid Anal Prev. 2008;40:1418-23.

23. Witt WP, Fortuna $L, W u$ E, Kahn RS, Winickoff JP, Pirraglia PA, et al. Children's use of motor vehicle restraints: maternal psychological distress, maternal motor vehicle restraint practices, and sociodemographics. Ambul Pediatr. 2006;6:145-51.

24. Okamura K, Mori K, Mitsui T. Factors influencing premature graduation from the use of child restraints in Japan. Accid Anal Prev. 2010;42:403-11.

25. Simpson JC, Turnbull BL, Stephenson SC, Davie GS. Correct and incorrect use of child restraints: results from an urban survey in New Zealand. Int J Inj Contr Saf Promot. 2006;13:260-3.

26. Morris SD, Arbogast KB, Durbin DR, Winston FK. Misuse of booster seats. Inj Prev. 2000;6:281-4.

27. Purc-Stephenson RJ, Ren J, Snowdon AW. An exploratory study of parents' use and knowledge of car safety seats in Beijing, China. Int J Inj Contr Saf Promot. 2010;17:231-8.

28. Desapriya EB, Pike I, Joshi P. Prices and affordability in child restraint seats in Japan. Inj Prev. 2005;11:125.

29. Du W, Finch CF, Bilston LE. Evidence to support changes to child restraint legislation. Med J Aust. 2008;189:598-9.

30. Zaza S, Sleet DA, Thompson RS, Sosin DM, Bolen JC; Task Force on Community Preventive Services. Reviews of evidence regarding interventions to increase use of child safety seats. Am J Prev Med. $2001 ; 21: 31-47$

Correspondence:

Sergio Ricardo Lopes de Oliveira

Rua Mem de Sá, 1899, casa 5, Vila Bosque

CEP 87005-010 - Maringá, PR - Brazil

Tel. : + 55 (44) 9911.7643, +55 (44) 3031.1403,

+55 (44) 2101.9119

E-mail: sergiolopes.uem@gmail.com 